\title{
Chest pain in paediatrics: single centre experience
}

\author{
${ }^{*}$ Suliman Almesned ${ }^{1}$, Ali Al-Akhfash ${ }^{2}$, Abdulrahman Almisnid ${ }^{3}$, Fahad Almesned ${ }^{4}$
}

Sri Lanka Journal of Child Health, 2021; 50(1): 83-86

\begin{abstract}
Introduction: Unlike in adults, chest pain in children is usually benign, although it can be a cause of anxiety to the child and family.
\end{abstract}

Objective: Long term follow up of paediatric cases, referred to our clinic because of chest pain, since we started the paediatric cardiology service in PSCC-Qassim in 2006.

Method: A retrospective review was done of all children referred with a complaint of chest pain to the paediatric cardiology service in PSCC-Qassim from 2006 to 2018. Data were collected from the department database. Families were contacted to find out about the child's chest pain and any other medical problems.

Results: Two hundred and forty two children were referred to our clinic for evaluation of chest pain from 2006. Of them 56\% were girls. The mean age at referral was $9.1 \pm 2.4$ years and the mean weight at referral was $30 \pm 12 \mathrm{~kg}$. On initial presentation, only $6.6 \%$ patients reported that the chest pain had some relation to exercise. The commonest symptom was palpitation. On clinical examination, $20.6 \%$ patients had innocent murmurs. The electrocardiogram (ECG) was normal in 231 $(95.4 \%)$ of the cases. Two hundred and nineteen $(90.5 \%)$ cases had normal echocardiographic findings. There was no statistical significance between the presence of a murmur and abnormal echocardiographic findings. Follow up was done

\footnotetext{
${ }^{1}$ Assistant Professor, Department of Surgery, Medical College, Qassim University, Saudi Arabia. ${ }^{2}$ Consultant Paediatric Cardiologist, Prince Sultan Cardiac Centre, Qassim, Saudi Arabia, ${ }^{3}$ Consultant Pediatric Cardiologist, University of Alberta Fellowship of Pediatric Cardiology and Centre Director Prince Sultan Cardiac Centre, Qassim, Saudi Arabia. ${ }^{4}$ Medical Student, Medical College, Qassim University, Saudi Arabia

*Correspondence: sulamansaud@gmail.com
}

https://orcid.org/0000-0002-0370-2003 (Keceived on 16 March 2020: Accepted after revision on 24 April 2020)

The authors declare that there are no conflicts of interest

Personal funding was used for the project.

Open Access Article published under the Creative

Commons Attribution CC-BY (c) (i)

License through telephone contact of families of cases seen in the clinic. The mean age at follow up was $12.8 \pm$ 3.3 years. One hundred and ninety five $(80.6 \%)$ stated that their children no longer have any chest pain. Forty eight $(19.8 \%)$ reported that their children still had nonspecific chest pain that did not interfere with their day to day activities. Thirteen (5.4\%) stated that their children had other medical problems like asthma, anaemia and hyperthyroidism. None of them reported sudden cardiac death in any of the children.

Conclusions: In this study carried out in the paediatric cardiology service in PSCC-Qassim, chest pain in children was benign. Follow up reported no sudden cardiac deaths in any of our cases.

DOI: http://dx.doi.org/10.4038/sljch.v50i1.9407

(Key words: Chest pain, paediatrics, palpitation, sudden cardiac death).

\section{Introduction}

Unlike in adults, chest pain in children is usually benign but can cause anxiety to child and family ${ }^{1}$. It can be due to cardiac or non-cardiac causes. Non-cardiac chest pain is more frequent in children and adolescents. Health care workers should be aware of the pathological causes of chest pain related to the cardiovascular, respiratory, gastrointestinal, or musculoskeletal systems ${ }^{2}$.

\section{Objective}

The objective of the study is long term follow up of paediatric cases, referred to our clinic because of chest pain, since we started the paediatric cardiology service in PSCC-Qassim in 2006.

\section{Method}

A retrospective review was done of all children referred with a complaint of chest pain to the paediatric cardiology service in PSCC-Qassim from 2006 to 2018. Data were collected from the department database. Families were contacted to find out about the child's chest pain and any other medical problems. Data were collected and then analysed using the SPSS programme.

Ethical issues: Ethical approval was obtained from the Institutional Research Committee (IRB) of Qassim University, Saudi Arabia (No. 20181019) on 29.10.2018. Informed written consent was 
obtained from the parents of the children participating in the study,

\section{Results}

Two hundred and forty two children were referred to our clinic for evaluation of chest pain from 2006. One hundred and thirty five (56\%) were girls. Ages ranged from 2-14 years (mean $9.1 \pm 2.4$ years). The weight at referral was 5 to $71 \mathrm{~kg}$ (mean $30 \pm 12$ $\mathrm{kg})$. (Table 1).

On initial presentation, only $16(6.6 \%)$ patients reported that the chest pain was related to exercise. Commonest symptom was palpitations (Table 2).

Table 1: Descriptive statistics for children with chest pain

\begin{tabular}{|l|c|c|c|c|}
\hline & Minimum & Maximum & Mean & Standard deviation \\
\hline Age of presentation (years) & 2 & 14 & 9.11 & 2.427 \\
\hline Weight at presentation (kg) & 5 & 71 & 29.86 & 12.110 \\
\hline Current age (years) & 4 & 22 & 12.79 & 3.297 \\
\hline
\end{tabular}

Table 2: Associated symptoms for children with chest pain $(n=242)$

\begin{tabular}{|l|c|}
\hline \multicolumn{1}{|c|}{ Symptom } & Frequency (\%) \\
\hline Palpitation & $16(06.6)$ \\
\hline Shortness of breath with bluish discolouration & $02(0.8)$ \\
\hline Syncopal attack & $01(0.4)$ \\
\hline Total & $19(07.2)$ \\
\hline
\end{tabular}

On clinical examination, $50(20.6 \%)$ patients had innocent murmurs with normal general, cardiovascular and other systems examination. The electrocardiogram (ECG) was normal in 231 $(95.4 \%)$ of the cases (Table 3$)$.
Two hundred and nineteen $(90.5 \%)$ paediatric cases referred to the clinic with chest pain had normal echocardiographic findings (Table 4).

Table 3: Electrocardiographic (ECG) findings $(n=242)$

\begin{tabular}{|l|c|}
\hline \multicolumn{1}{|c|}{ ECG findings } & Frequency (\%) \\
\hline Borderline prolonged QT 480, incomplete right bundle branch block & $01(0.4)$ \\
\hline Ectopic atrial rhythm & $01(0.4)$ \\
\hline Frequent premature ventricular contractions & $02(0.8)$ \\
\hline Normal sinus rhythm & $231(95.4)$ \\
\hline Normal sinus rhythm, right bundle branch block & $01(0.4)$ \\
\hline Normal sinus rhythm, 1st degree heart block & $03(01.2)$ \\
\hline Sinus bradycardia, ST elevation & $01(0.4)$ \\
\hline Sinus rhythm with right axis deviation with RAE and evidence of RVH & $01(0.4)$ \\
\hline Sinus rhythm, left axis deviation, infrequent premature atrial contractions & $01(0.4)$ \\
\hline
\end{tabular}

$R A E=$ Right atrial enlargement, $R V H=$ Right ventricular hypertrophy

Table 4: Echocardiographic (EEG) findings $(n=242)$

\begin{tabular}{|l|c|}
\hline \multicolumn{1}{|c|}{ Echocardiographic findings } & Frequency (\%) \\
\hline Bicuspid aortic valve & $04(01.6)$ \\
\hline Mitral valve prolapse & $05(02.0)$ \\
\hline Thickening of the tip of anterior mitral valve leaflet with mild MR (posterior jet) & $02(0.8)$ \\
\hline Secundum atrial septal defect & $02(0.8)$ \\
\hline Abnormal septal motion & $01(0.4)$ \\
\hline Mild right sided dilatation. Mild TR, PG =22 mm Hg, Mild PR, trivial MR & $01(0.4)$ \\
\hline Moderate pericardial effusion & $01(0.4)$ \\
\hline Partial anomalous pulmonary venous drainage & $01(0.4)$ \\
\hline Patent foramen ovale Vs Secundum atrial septal defect & $03(01.2)$ \\
\hline Trivial mitral regurgitation & $01(0.4)$ \\
\hline Small outlet ventricular septal defect & $02(0.8)$ \\
\hline Normal & $219(90.5)$ \\
\hline
\end{tabular}

$M R=$ Mitral regurgitation, $T R=$ Tricuspid regurgitation, $P G=$ Pressure gradient, $P R=$ pulmonary regurgitation 
Correlation between the echocardiographic findings and the presence of a cardiac murmur revealed that $35(14.5 \%)$ cases had a murmur with normal echocardiographic findings and $10(4.1 \%)$ cases had a murmur with some cardiac abnormalities (Table 5). There was no statistical significance between the presence of a murmur and abnormal echocardiographic findings.

Table 5: Echocardiographic and cardiac examination cross tabulation $(n=242)$

\begin{tabular}{|l|c|c|c|}
\hline \multicolumn{1}{|c|}{ Echocardiographic findings } & Cardiac examination & Total \\
\hline Atrial septal defect & Normal & Systolic murmur & 02 \\
\hline Bicuspid aortic valve & 01 & 01 & 03 \\
\hline Mitral valve prolapse & 01 & 02 & 08 \\
\hline Mild diastolic dysfunction & 05 & 03 & 01 \\
\hline Muscular ventricular septal defect & 01 & 0 & 02 \\
\hline Normal & 0 & 02 & 224 \\
\hline Partial anomalous pulmonary venous drainage & 189 & 35 & 01 \\
\hline Trivial mitral regurgitation & 0 & 01 & 01 \\
\hline
\end{tabular}

Through telephone contact of families of cases seen in the clinic, the current age range of the study population is $4-22$ years (mean $12.8 \pm 3.3$ years). One hundred and ninety five $(80.6 \%)$ stated that their children no longer have any chest pain. Forty eight $(19.8 \%)$ reported that their children still had nonspecific chest pain that did not interfere with their day to day activities. Thirteen (5.4\%) children stated that they had medical problems like asthma, anaemia and hyperthyroidism (Table 6). There were no reported sudden cardiac death in any one of those contacted.

Table 6: Condition on follow up $(n=242)$

\begin{tabular}{|l|c|}
\hline Condition on Follow up & Frequency (\%) \\
\hline Anaemia and vitamin deficiency & $01(0.4)$ \\
\hline Bronchial asthma & $06(02.4)$ \\
\hline Behcet disease & $01(0.4)$ \\
\hline Eye disease & $01(0.4)$ \\
\hline Normal & $220(90.9)$ \\
\hline Palpitations & $09(03.7)$ \\
\hline Had cardiac intervention (Atrial septal defect closure) & $01(0.4)$ \\
\hline Sick cell anaemia & $01(0.4)$ \\
\hline Thyrotoxicosis & $02(0.8)$ \\
\hline
\end{tabular}

\section{Discussion}

Chest pain is a frequent symptom in children. It is the next frequent cause of referral to paediatric cardiologists after cardiac murmur ${ }^{3}$. Although, in contrast to adult populations, it is rarely associated with serious cardiac diseases, it might lead to major parental concerns and worries and also extensive investigations ${ }^{1,3}$. In some reports, cardiac diseases causing chest pain were identified in $0.48 \%$ of cases $^{4}$. In our study we identified minor CHD in 23 $(9.5 \%)$ patients. One patient had pericardial effusion, and 8 patients had mitral valve prolapse (MVP) which might explain the chest pain symptoms. The other disorders are less likely to cause chest pain. MVP might cause nonspecific symptoms which might be interpreted by the patient as chest pain or discomfort ${ }^{5}$. MVP was diagnosed in $8(3.3 \%)$ of our patients.
It is advised to use a standardized clinical assessment and management plan (SCAMP algorithm) for assessing children with chest pain. This will reduce the use of unnecessary investigations and referrals of such patients ${ }^{3,4,6}$. It is reported that the paediatric outpatient assessment of patients with chest pain with cardiac pathology can be identified using the SCAMP algorithm ${ }^{6}$. SCAMPs currently exist to treat many different clinical conditions in a variety of clinical settings for the paediatric population including chest pain ${ }^{7}$.

Follow up of chest pain in children does not reveal an increased risk of sudden cardiac death ${ }^{8,9}$. In our cases, all of the cases contacted are having a normal lifestyle with no restriction of daily activities. Some of them are having some medical problems like bronchial asthma. There are no reported sudden cardiac deaths in any of our cases. 


\section{Conclusions}

In this study carried out in the paediatric cardiology service in PSCC-Qassim, chest pain in children was benign. Follow up reported no sudden cardiac deaths in any of our cases.

\section{References}

1. Friedman KG, Kane DA, Rathod RH, Renaud A, Fanas M, Geggel R, et al. Management of paediatric chest pain using a standardized assessment and management plan. Pediatrics 2011; 128(2): 239-45.

https://doi.org/10.1542/peds.2011-0141

PMid: 21746719

2. Rowe BH, Dulberg CS, Peterson RG, Vlad P, Li MM. Characteristics of children presenting with chest pain to a pediatric emergency department. Canadian Medical Association Journal 1990; 143(5): 388-94.

3. Verghese GR, Friedman KG, Rathod RH, Meiri A, Saleeb SF, Graham DA, et al. Resource utilization reduction for evaluation of chest pain in paediatrics using a novel standardized clinical assessment and management plan (SCAMP). Journal of the American Heart Association 2012; 1(2): pii: https://doi.org/10.1161/JAHA.111.000349 PMid: 23130120 PMCid: PMC3487367

4. Harahsheh AS, O'Byrne ML, Pastor B, Graham DA, Fulton DR. Paediatric chest pain-low-probability referral: A multiinstitutional analysis from standardized clinical assessment and management plans (SCAMPs), the paediatric health information systems database, and the national ambulatory medical care survey. Clinical Pediatrics (Phila) 2017; 56(13):1201-8. https://doi.org/10.1177/000992281668460 5

PMid: 28081617 PMCid: PMC6388765

5. Bowen RC, D'Arcy C, Orchard RC. The prevalence of anxiety disorders among patients with mitral valve prolapse syndrome and chest pain. Psychosomatics 1991; 32(4):400-6. https://doi.org/10.1016/S00333182(91)72 041-0
6. Kane DA, Friedman KG, Fulton DR, Geggel RL, Saleeb SF. Needles in Hay II: Detecting cardiac pathology by the paediatric chest pain standardized clinical assessment and management plan. Congenital Heart Disease 2016; 11(5):396-402.

https://doi.org/10.1111/chd.12335

PMid: 26918410

7. Farias M1, Jenkins K, Lock J, Rathod R, Newburger J, Bates DW, et al. Standardized clinical assessment and management plans (SCAMPs) provide a better alternative to clinical practice guidelines. Health Affairs (Millwood) 2013; 32(5):911-20.

https://doi.org/10.1377/hlthaff.2012.0667

PMid: 23650325 PMCid: PMC3990928

8. Saleeb SF1, Li WY, Warren SZ, Lock JE. Effectiveness of screening for lifethreatening chest pain in children. Pediatrics 2011; 128(5):e1062-8. https://doi.org/10.1542/peds.2011-0408 PMid: 21987702

9. Cohn HE, Arnold LW. Chest pain in young patients in an office setting: cardiac diagnoses, outcomes, and test burden. Clinical Pediatrics (Phila) 2012; 51(9):877-83. https://doi.org/10.1177/000992281245165 0

PMid: 22752294 